\title{
EL OFICIO DE MUJER EN LA PEQUEÑA NOBLEZA URBANA DEL SIGLO XVII ESPAÑOL
}

\author{
Pilar BERNABEU NAVARRET \\ Universidad de Alicante
}

Este artículo es una sucinta mirada retrospectiva a través de tres siglos hacia las funciones que desempeñaban las mujeres de la pequeña nobleza urbana del Seiscientos que permanecían "en el siglo" y seguían el camino del matrimonio. Su intención es analizar los tres roles que se les asignaban convencionalmente y mostrar cómo no siempre constreñían su acción a los estrechos límites establecidos por el sistema social.

El punto de partida de nuestro trabajo son los datos proporcionados por una fucnte que, tratada con el cuidado que exigen los documentos literarios, resulta de extraordinario valor: la novela barroca ${ }^{1}$. Este género literario ha recibido por nuestra parte una atención que se ha visto compensada con creces por la información que ha aportado a nuestra memoria de licenciatura, en la que tratamos entre otros muchos temas el que nos ocupa en el presente artículo².

Las funciones que debían llevar a cabo las mujeres de ese grupo social estaban bien delimitadas por los preceptistas y moralistas, cuyas obras tuvicron un amplio éxito en el siglo XVII. Fray Luis de León había escrito en el siglo anterior un manual de moral, La perfecta casada, cuyos principios valían, salvando las distancias, para el grupo social que nos interesa:

"Servir al marido y el gobernar la familia y la crianza de los hijos, y la cuenta que juntamente con esto se debe al temor de Dios, y la guarda y limpieza de la conciencia (todo lo cual pertenece al estado y oficio de la mujer casada) $[\ldots]^{\prime 3}$

Podríamos resumirlo así: gobierno doméstico, reproducción biológica y reproducción de pautas de conducta. Pero ese planteamiento teórico debía, como ya hemos 
dicho, salvar las distancias, puesto que la mujer que Fray Luis de León proponía como modelo de virtud era la campesina hacendosa y recogida que se movía en un entorno muy diferente al de la mujer urbana acomodada.

De hecho, la forma en que la mujer de la pequeña nobleza urbana ejercía el gobierno doméstico se alejaba bastante de la laboriosidad de la campesina. Era el servicio el que se ocupaba materialmente de la habitabilidad y el buen funcionamiento de la casa.

"Yo era el regocijo de la casa, porque yo mandaba en ella. Lo que yo hacía era lo más acertado; lo que yo mandaba, lo obedecido. Era dueño de la hacienda y de cuya era. Por mí se despedían y recibían los criados."4

En esta cita se puede observar que lo que distinguía a la dueña de la casa era su poder sobre los criados; que mandaba y era obedecida, que decidía quiénes le iban a servir y quiénes tenían que marcharse. Este papel director quedaba completado si era necesario por su atención personal, de la que era objeto especialmente el cabeza de familia, verdadero dueño y señor ante el que la mujer debía responder. Esta función se pone de maniliesto en la siguiente cita de La injusta ley derogada, siendo ejercida por las hijas para el padre viudo:

"Ya tenía dada orden a Otavio, mi primo, que en compañía de dos criados suyos y una criada mía me embarcase luego, que él quedaba en compañía de una hermana mía menor que le sirviese y regalase." 5

En un fragmento de El amante venturoso encontramos referencia tanto al aspecto de la atención personal al padre como al del gobierno de los criados:

"Dando de cenar a su padre y orden a lo restante de su gobierno, mientras cenaban las criadas, se retiró a su recogimiento."6

La realidad es que el liempo y el esfuerzo que requerían las funciones doméslicas de la mujer noble eran bastante escuetos, y podían ser mínimos si ésta no se sentía especialmente atraída por aplicarse a ello. Era del todo impensable en la mentalidad nobiliaria que una mujer noble hiciera por sí misma las faenas de la casa, reservadas a los criados. En El traidor contra su sangre se hace evidente que hacer las faenas de la casa era lo último, y señal de una penuria total:

"Vino a tal estado la miseria, que despidiendo a las criadas, se humilló a servir su casa, si tal vez la criada de su madre la excusaba con acudir a servirla."7

Recordemos que el ejercicio de una actividad manual para ganarse el sustento era una tacha innoble y se trataba de evitar siempre que fuera posible. Al tener cria- 
dos que se ocuparan de las tareas domésticas, las mujeres nobles se libraban de ellas al mismo tiempo que la familia podía hacer ostentación de una buena posición cconómica, pues una gran servidumbre era signo de riqueza.

Había sin embargo un tipo de actividades hogareñas que sí se consideraban dignas y recomendables para una mujer noble. Se trataba de las labores finas, singularmente el bordado, que no exigían gran agilidad mental, aunque sí habilidad manual, paciencia y dedicación. No se trataba de un trabajo realizado para ganarse la vida (aunque en otras circunstancias económicas hubiese bordadoras que vivían de su trábajo), puesto que su fruto se destinaba a embellecer y hacer más cómodo el hogar o a obsequiar al varón.

"Teodora, por los continuos y prolijos achaques de su padre, no salía de casa, y a las horas que Ricardo faltaba a la suya, se iba con su amiga; entretenidas las dos en el curso de sus curiosas labores." 8

En la novela barroca las mujeres aparecen frecuentemente ocupadas en bordar, apoyadas en su inseparable almohadilla, recogidas, concentradas y en silencio ¿Qué mcjor actitud se podía pedir a una mujer? Era en cierta forma una garantía de que no se dedicaba a otras liviandades, como la protagonista de Los hermanos amantes, de Guevara:

"Ella no trataba más que de asistir a la ventana y pocas veces la almohadilla era empleo de sus manos." 9

Las labores y el gobierno doméstico eran las actividades idóneas para la mujer, habilidades indispensables en su formación y asociadas a la condición femenina de manera que era impensable que un hombre se dedicara a ellas.

La segunda función asignada a la mujer era la de la reproducción biológica y la crianza de los hijos. En la pequeña nobleza urbana, la llegada de éstos era un acontecimiento esperado y deseado en cuanto se producía cl matrimonio. En el seno de una familia noble y acomodada, aparte de sus implicaciones afectivas, un nacimiento significaba la perpetuación del honor y el patrimonio familiar en la persona del nuevo ser. En él se depositaban las expectativas de su conservación y engrandecimiento, y no había peor desgracia para una familia que la ausencia de un sucesor, hecho que apremiaba la búsqueda de un cónyuge adecuado para las hijas:

"Con la ausencia de su amante no hallaba consuelo alguno, sólo lo que podía dárselo era ver muerto a su primo don Jaime, que era con quien su padre instaba que se casase para que el apellido de su casa no se perdiese." 10

"Hija mía, nuestra vida es incierta, yo tengo larga edad y mi casa se halla sin sucesor, causas que me han obligado a buscarte esposo." 11 
Los hijos no se hacían esperar una vez celebrado el matrimonio, y a partir de su nacimiento los padres ya empezaban a hacer planes sobre su futuro. Algo muy distinto ocurría si los hijos nacían fuera del matrimonio, pero la situación era muy diferente según la ilegitimidad viniese por parte del marido o de la mujer. El hombre podía tener hijos ilegítimos sin que éstos interfirieran para nada en la sucesión del apellido y la hacienda familiar, ya que la ilegitimidad suponía una inferioridad de derechos en este campo, a no ser que los legitimase y voluntariamente quisiera reconocerles algunos derechos. ${ }^{12}$ No peligraba en absoluto la pureza de la sangre familiar porque estaba claro que la esposa legítima no era la madre, y en el aspecto moral el adulterio masculino estaba bastante tolerado.

Otra cosa era que la mujer engendrara un hijo ilegítimo. El adulterio era uno de los delitos más graves y más duramente castigados en los que podía incurrir una mujer. Esta posibilidad inspiraba un agudo temor, porque determinar la paternidad se prestaba a engaño o a confusión y de esa forma podía producirse la intrusión de sangre extraña y quizá plebeya en la familia. De ahí que el recelo y la vigilancia sobre la mujer fueran intensas.

Cuando no existían estos temores en torno a la llegada de un hijo, ésta era una grata noticia pese a la extrema peligrosidad y el sufrimiento que conllevaba cl alumbramiento. Una vez superado éste y las altas posibilidades de mortalidad en las fechas posteriores, el niño empezaba a recibir los cuidados oportunos, el primero de los cuales era su alimentación: la lactancia. A pesar de las encarecidas recomendaciones de todos los tratadistas de la época, ésta quedaba relegada habitualmente a otras personas que no eran la madre. ${ }^{13}$ Muchas mujeres nobles obviaban esta obligación por comodidad, por costumbre y porque parecía de buen tono. Entre los numerosos alegatos a favor de la lactancia materna cabe citar el que hace Juan Gutiérrez de Godoy en 1629 en su obra Tres discursos para probar que están obligadas a criar a sus hijos a sus pechos todas las madres cuando tienen buena salud, fuerzas, temperamento, buena leche y suficiente para alimentarlos. ${ }^{4} \mathrm{El}$ larguísimo título ofrece por sí solo todo un pliego de condiciones como para desanimar a cualquiera y surtir de excusas varias a las madres reticentes. El hecho es que de la lectura de la novela barroca se desprende que las amas de cría cran un clemento habitual del servicio doméstico. Estas nodrizas amamantaban al niño en los primeros años de vida, ya que la lactancia era bastante prolongada, quitando así a la madre una de sus mejores formas de relación con el pequeño. Los nobles solían tener su propia nodriza en casa, que podía ser profesional o una sirvienta que había tenido un hijo.

"A tres meses de casada se reconoció preñada, colmando la fortuna su dicha con el mucho gusto de su amado esposo. Estaba Rosenda [una criada] preñada de seis meses [y] se determinó que fuera ama de lo que la duquesa pariese. (...) Llegado el tiempo, parió Rosenda una niña que fue llamada Eulrasia, y la duquesa parió otra a quien llamaron Venus."15 
También había madres dispuestas a cumplir con las obligaciones de la lactancia, pero fijémonos cómo se trataba de un deseo personal de alguna madre celosa de sus deberes:

"A los nueve meses les dio el cielo un hijo el cual doña Ana, muy madre, quiso criar a sus pechos." 16

Sin embargo, en el mismo relato poco después ocurre que, ante la ausencia de la madre, se ha de buscar una nodriza, y la prontitud con que aparece da fe de la naturalidad con que se confiaba a otras mujeres el amamantar a los niños:

"La señora tomó al nieto, y llamando a una vecina que le diese de mamar, le aquictó y adormeció."17

En los años siguientes, si el niño sobrevivía, no hemos de esperar que recibiese una afectividad y solicitud maternal como la que es proverbial hoy en día. Esta actitud empczaba precisamente entonces a perfilarse especialmente entre ciertos grupos sociales, entre los que se cuenta la pequeña nobleza urbana. Contribuyeron a ello la evolución de la vida privada, la mentalidad y las formas de relación que tuvo lugar a lo largo de la Edad Moderna. ${ }^{18} \mathrm{~A}$ este respecto Philippe Ariés opinaba que todavía no sc había producido o estaba empezando a producirse la individualización del niño como ser distinto al adulto. ${ }^{19} \mathrm{La}$ alta mortalidad llevaba a desconfiar de las posibilidades de supervivencia y no favorecía el encariñamiento. Cuando se consideraba pasado el peligro de muerte, el niño recibía un trato apenas diferente al de los adultos, introduciéndolo paulatinamente en su mundo sin pasos intermedios diferenciados.

La escasa afectividad que existía entre la mayoría de madres e hijos se veía facilitada por constituir el cuidado de los niños una parte más de las funciones de los criados. Había sirvientes especiales para ello y la atención personal de la madre podía ser, de nuevo, puntual y para asegurarse el acabado de un buen trabajo, aunque todo dependía, como es de suponer, de su sensibilidad personal. De todos modos, la preocupación por la crianza de los hijos tenía en las madres de la pequeña nobleza urbana las mejores condiciones para su desarrollo, ya que disponían de un ticmpo y unos recursos de los que carecían las de niveles sociales inferiores, más ocupadas en necesidades inmediatas, y las de niveles sociales superiores, por lo poco que favorecía la intimidad familiar la forma de vida de la alta nobleza.

Un tercer y no poco importante apartado de las funciones de la mujer en la pequeña nobleza urbana era el de la reproducción de pautas de conducta en sí misma y en sus hijos. Nos referimos al proceder noble que llevaba aparejada la posesión del honor. La mujer debía comportarse y dar una imagen acorde con la nobleza de la casa asumiendo las tareas y las formas de actuación que le eran propias. Esa es la opción que toma la protagonista un tanto díscola de una obra de Castillo Solórzano, que finalmente se aplica a ejercer como competía a una doncella: 
"Pues con lo que le había sucedido a la infanta no quiso proseguir con la caza, antes desde aquel día, por esto, se fue olvidando de aquel ejercicio, ocupándose más en los pertenecientes a las damas que son los de sus labores y curiosidades dentro de sus casas." 20

Esas pautas de conducta debían respetarse más si cabe en el caso de las familias enriquecidas que aspiraban a conseguir la hidalguía o, poseyéndola, intentaban trepar a escalones más altos de nobleza. Además las mujeres debían inculcar a sus hijas esa forma de actuar y velar por que no se desviaran de ese camino.

Los actos femeninos debían guiarse por la obediencia al cabeza de familia, la salvaguarda de la fama, el sometimiento a los intereses familiares, la honestidad... Este último punto era fundamental, pero no bastaba con ser honesta; había que parecerlo. La mujer debía ofrecer al público una imagen honesta y honorable tanto de sus actos como de su persona. La belleza y ornamentación personal se consideraban atributos de nobleza, como se desprende de estas citas de El amante venturoso y La Venus de Ferrara, de Mariana de Carvajal:

"Apostando lucimientos en que Teodora, como en espejo cristalino, reconociera los altos merecimientos de su ilustre sangre, la singular hermosura tan celebrada de todos, que la llamaron el milagro de aquel tiempo."21

"Puso los ojos en las dos labradoras, y mirando que traían velos en los rostros y lucidas galas, presumió serían algunas damas principales que venían disfrazadas"22

En consecuencia, sus buenas maneras, sus cualidades, sus vestidos, su arreglo personal, su compostura, su lenguaje, sus aderezos y la riqueza de sus objetos personales debían publicar su condición a los cuatro vientos. No se trataba sólo de una mujer. Era la esposa, la hija, la madre o la viuda de un personaje cuya casa debía brillar a la altura que se merecía y, en cierta forma, un símbolo viviente.

Las funciones que hemos analizado limitaban al hogar el campo de actuación de la mujer y la separaban de la actividad económica y política de la vida pública. De esta forma, dentro de los estamentos sociales que tenían algún tipo de poder, se quitaba a la mujer vías de intervención legal y ordinaria en las decisiones reservadas a los hombres. Esta desigualdad estaba consagrada por las leyes y las doctrinas morales, y por lo tanto institucionalizada y sacralizada.

Tanto los derechos forales como el castellano se apoyaban en el tronco común romano que consideraba al sexo femenino débil y simple, y por lo tanto le daba un tratamiento diferente. ${ }^{23}$ La diferencia conducía -claro está- al apartamiento de la vida social y la subordinación al varón. En Castilla las leyes de Toro de principios del siglo XVI estipulaban que la mujer casada no podía repudiar una herencia, ni hacer contratos, ni estar en juicio sin la licencia de su esposo. Sí podía, en cambio, aceptar una herencia con beneficio de inventario. Pero quedan en el aire muchas acciones jurídicas no contempladas en las leyes ${ }^{24}$. 
Sale aquí a colación el problema de las lagunas, la imprecisión y la ambigüedad de las leyes vigentes en el siglo XVII. Esto impide determinar clara y objetivamente las limitaciones legales de la actividad femenina. Hay que tener en cuenta la dispersión de las leyes y ordenanzas emanadas de diferentes autoridades, las diferencias territoriales y la importancia de los usos consuetudinarios. La situación en que quedaba la mujer en este complejo panorama no ha sido todavía objeto de un estudio global adecuado. Veamos lo que ocurre, por ejemplo, en lo referente a la prohibición de desempeñar cargos jurisdiccioneales, un aspecto significativo de la situación jurídica de la mujer señalado por Enrique Gacto:

"Donde la limitación de la capacidad jurídica de la mujer encuentra un reflejo paradigmático es en la prohibición de desempeñar cargos que lleven aparejada jurisdicción y, en general, cualquier oficio público, o la de ejercer el empleo de abogado y el de procurador, profesiones que no pueden practicar porque, según la ley "cuando las mujeres pierden la vergüenza es cosa fuerte el oirlas o el contender con ellas"25

Las razones aducidas por el jurista citado pueden incluso resultar risibles desde nuestra óptica actual, pero debemos tener en cuenta que se basaban en la mala naturaleza de la mujer, un principio jurídico como lo puede ser hoy día la igualdad de sexos, y que en su momento eran lo bastante convincentes para no necesitar más justificación. Se daba por hecho que la mujer no podía acceder a cargos públicos y que nadie lo iba a dudar, pero este planteamiento conducía a la imprecisión en la legislación, como señala Felipe Lorenzana citando la Novísima recopilación:

"No crecmos que existiese, sin embargo, prohibición expresa, sino más bien presupuesta exclusión: "porque los oficios públicos (...) conviene que se den y provean a personas hábiles, varones prudentes" 26

Este autor, que ha estudiado la presencia de la mujer en el municipio de Badajoz en el siglo XVII a través de los traspasos de regidurías, puntualiza la prohibición de ejercer oficios públicos y señala algunos resquicios jurídicos a través de los cuales podía darse cierta participación femenina en la vida municipal, facultades que fueron bien utilizadas por las mujeres. La compraventa de cargos municipales les permitía, si no ejercer directamente, sí controlar según su voluntad al titular del oficio del que eran propietarias. 27

Podemos decir, a la vista de lo ya expuesto, que las limilaciones legales no cerraban totalmente el paso a la participación de la mujer en la vida económica, política, en actos jurídicos o administrativos desbordando su campo teórico de actuación. La novela barroca proporciona numerosos ejemplos, la mayoría de los cuales corresponden a viudas. 
"En este tiempo murió su padre, dejando a sus hermosas hijas con gran suma de riqueza y a su madre por su amparo. La cual, ocupada en el gobierno de su hacienda, no trató de darlas estado en más de dos años."28

La viuda de este relato descuida precisamente la atención al matrimonio de sus hijas, deber más próximo al ámbito femenino, por volcarse en una actividad más propiamente masculina, el gobierno de la hacienda. Es una mujer que a la muerte de su marido ha quedado en buena posición económica, pero entre la pequeña nobleza urbana no siempre se contaba con patrimonios que posibilitaran una viudez desahogada. Uno de los recursos más utilizados entonces por las viudas era el alquiler de sus casas. Esta actividad proporcionaba unos ingresos apreciables sin que la mujer tuviera que rebajarse a trabajar para otros ni salir del ámbito privado.

"Tomó cuarto frontero de mis casas, en casa de una viuda que vivía con el alquiler que los estudiantes le pagaban" 29

También encontramos mujeres que actúan como intermediarias:

"Entrando en la primera sala hallaron en un estrado una señora viuda rezando en unas horas (...). La anciana dijo que la casa no era suya más que por cinco meses; tenía facultad para poder alquilar lo que estaba vacío, por haberlo dejado una amiga suya que se había ido de la corte, pero que satisfaciéndoles la vivienda de él, sería fácil concertarse con el dueño de la casa, que era un apacible hidalgo rico y no era nada tirano. Díjoles cuánto daban por él y que habían de dar ellas menos, y así se efectuó el concierto y se le dio la señal, como es costumbre." 30

No sólo encontramos a las mujeres percibiendo alquileres, sino realizando transacciones más complejas como pedir un préstamo con la garantía de sus joyas:

"- Señor doctor, yo tengo seis mil escudos en poder de los Fúcares y en plata. Cuando los dejé allí para que ganasen, me pusieron por condición que cuando los quisiera yo sacar de su poder, les había de avisar un mes antes; (...) pero como no se puede hacer más, quiero valerme de mis joyas, que son de consideración y bastantes para pedir más cantidad; helas hecho lasar por el contraste y esta es su fe." 31

Las referencias halladas en la novela barroca sugieren una actividad femenina mayor de la que hacer pensar las leyes tanto por las lagunas que éstas dejaban o la ausencia del varón como por la existencia de vías de influencia en las decisiones masculinas teóricamente ajenas a la mujer, actividades que habría que rastrear en otro tipo de fuentes distintas a las literarias. Antonio Domínguez Ortiz opina que la mujer, aunque desprovista de fuerza legal, tenía una apreciable dosis de poder real en todos los ámbilos. 32 
Ese poder real de la mujer venía en parte por su capacidad de influir en las decisiones masculinas, reconocida por el propio Fray Luis de León:

"Pues la razón y palabra de mujer discreta es más eficaz que ninguna otra en los oidos del hombre, porque su aviso es aviso dulce. (...) Y muchas veces lo que la razón no puede la importunidad lo vence, y señaladamente la de la mujer, que como dicen los experimentados, es sobre todas." 33

Cuando fallaba la razón o la insistencia, quedaba el eficaz recurso de una buena llantina:

"Interrumpió, llegando aquí, con lágrimas su cuento lastimoso, y los oyentes, informados de otras circunstancias convenientes y movidos de una secreta fuerza, que para provocar a misericordia más que el hombre encierra en sí cualquier mujer"'34

La mujer ponía en marcha si era necesario las tretas y subterfugios que le permitieran influir en las decisiones masculinas o librarse de ellas. De tales acciones hay un verdadero repertorio en la novela barroca. Y antes de despreciar estas "armas femeninas" habría que preguntarse, a falta de otros recursos, la influencia que llegaron a tener en la política española las palabras suaves y razonables, las llantinas y las tretas de algunas ilustres mujeres que se movían hábilmente por los pasillos de palacio.

\section{NOTAS}

1.- Dedicamos al análisis de la novela barroca como fuente para la Historia de la Mujer una comunicación que fue enviada al congreso El trabajo de las mujeres. Pasado y presente, organizado por el Seminario de Estudios Interdisciplinarios sobre la mujer de la Universidad de Málaga, celebrado entre el 1 y el 4 de diciembre de 1992; comunicación que titulamos "La novela barroca como fuente para la Historia de las Mujeres ", cuya publicación cn actas csperamos próximamente.

2.- Nuestra memoria de licenciatura, dirigida por el Doctor D. Mario Martínez Gomis, fue leída el 20 de junio de 1992 en la Universidad de Alicante y se tituló "La mujer en la pequeña nobleza urbana del siglo XVII español".

3.- LEON, Fray Luis de: La perfecta casada (1538) Atlas, Madrid, 1950, p. 211.

4.- ZAYAS, M.: “Engaños que causa el vicio", en Desengaños amorosos (1649), RAE, Madrid, 1950, p.439.

5.- CASTILlo SOlORZANO,A. : "La injusta ley derogada", en Fiestas del jardín (1634) Georg Olms, n. 1., 1973, p. 16. 
6.- CARVAJAL, M. :"El amante venturoso", en Navidades de Madrid y noches entretenidas (1663) Universidad de Verona, Milán, 1988, p. 89.

7.- ZAYAS, M.: "El traidor contra su sangre", en Desengaños amorosos (1649), op. cit. p.322 $-323$.

8.- CARVAJAL, M. :'El amante venturoso", en Navidades de Madrid y noches entretenidas (1663), Univ. de Verona, Milán, 1988, p. 86.

9.- GUEVARA, L. : "Los hermanos amantes", en RODR_GUEZ, E. (ed): Novelas amorosas de diversos ingenios del siglo XVII, Castalia, Madrid, 1988, colección Clásicos Castalia $\mathrm{n}^{\circ} 155$, p. 316.

10.- CASTILlo SOLÓRZANO, A. : "La vuelta del ruiseñor", en Fiestas del jardín (1634), Georg Olms, n.l., 1973, p. 169.

11.- CASTILllo SOLÓRZANO, A. : "La vuelta del ruiseñor", op. cit. p. 170.

12.- ÁLVAREZ SANTALÓ, L.C., hace referencia a la situación de los ilegítimos en "Anormalidad y códigos de conducta de la familia en el Antiguo Régimen: la doctrina religiosa sobre el abandono de niños", en CHAC_N, F. (ed): Familia y sociedad en el. Mediterráneo occidental, siglos XV - XIX, Univ. de Murcia, Murcia 1987.

13.- HERNÁNDEZ, $M^{a}$ A. : "La imagen de la mujer en la literatura moral y religiosa de los siglos XVI y XVII", en Norba, Universidad de Extremadura, Cáceres, 1987 - 1988, nº -9 , p. 183.

14.- Citado por Pedro y $\mathrm{M}^{a}$ José VOLTES en Madres y niños en la historia de España Planeta, Barcelona, 1989 , p. $78-79$.

15.- CARVAJAL,M. : "La Venus de Ferrara", en Navidades de Madrid y noches entretenidas(1663), Universidad de Verona, Milán, 1988, p. 51.

16.- ZAYAS, Ma: "El traidor contra sus sangre", en Desengaños amorosos, op. cit. p. 321.

17.- ZAYAS, Ma: "El traidor...” op. cit. ,p. 325.

18.- Hay abundantes referencias a este tema en la obra recopilatoria de ARIES, P. y DUBY, G.(eds): Historia de la vida privada, vols. 5 y 6, Taurus, Madrid, 1991.

19.- ARIES, P. : El niño y la vida familiar en el Antiguo Régimen, Taurus, Madrid, 1987.

20.- CASTILlO SOLÓRZANO, A. : "La crianza bien lograda" en Fiestas del jardín, op. cit. , p. $509-510$.

21.- CARVAJAL, M.: "El amante venturoso", en Navidades de Madrid y noches entretenidas, op. cit. , p. 86.

22.- CARVAJAL, M.: "La Venus de Ferrara", en Navidades de Madrid y noches entretenidas, op. cit., p. 46.

23.- GACTO, E. : "Entre la debilidad y la simpleza", en Historia 16, n¹45, mayo 1988, pp. 24 - 32; PÉREZ, I. y GIL, A. : "Fembras vils versus verges ideals", en L'Avenç, n" 142, 1990, p. 31.

24.- HERNÁNDEZ,Ma $M^{\text {A } A . ~: ~ " L a ~ m u j e r ~ e n ~ l a ~ l i t e r a t u r a ~ m o r a l ~ y ~ r e l i g i o s a ~ d e ~ l o s ~ s i g l o s ~ X V I ~ y ~}$ XVII", en Norba, Universidad de Extremadura, Cáceres, 1987 - 1988, n 8 - 9, p. 182.

25.- GACTO, E. : art. cit, p. 26

26.- LORENZANA, F.: "Sobre la incapacidad de las mujeres para ejercer oficios públicos. Las regidurías de Badajoz", en Norba, $\mathrm{n}^{\circ} 8$ - 9, op. cit., p. 189.

27.- LORENZANA, F. : art. cit. p. 19! - 192. 
28.- ZAYAS, M": "EI jardín engañoso", en REDONDO, A. Tres novelas amorosas y ejemplares y tres desengaños amorosos, Castalia - Instituto de la Mujer, Madrid, 1989, p. 175

29.- LOZANO, C. : Soledades de la vida y desengaños del mundo (1663), Madrid, 1812, soledad $\mathrm{I}$.

30.- CASTILlO SOlÓRZANO, A. : Las harpias en Madrid (1631), Castalia, Madrid, 1985, p. $54-55$.

31.- CASTILlO SOLÓRZANO, A.: "Estafa tercera", en Las harpias en Madrid, op. cit., p. $156-157$.

32.- DOMÍNGUEZ ORTIZ, A. : "La mujer en el tránsito de la Edad Media a Ia Edad Moderna", en SEGURA, (ed): Las mujeres en las ciudades medievales, Seminario de Estudios de la mujer de la UAM, Madrid, 1984, p. 177.

33.- LEÓN, Fray Luis de: La perfecta casada, op. cit. p. 241.

34.- CÉSPEDES Y MENESES, G. : "El buen celo premiado", en Historias peregrinas y ejemplares (1623), Castalia, Valencia, 1970, p. 72. 